\title{
Editorial: Alternative histories of electroacoustic music
}

In the more than twenty years of its existence, Organised Sound has rarely focused on issues of history and historiography in electroacoustic music research. Although some articles have adopted an explicitly historic perspective - often as the only such article within a given issue - many more have focused upon the documentation of current or recent creative practice and scientific research, the latest tools, techniques and software, or the development of new aesthetics, theory and analysis. Perhaps this should not be surprising given electroacoustic music's close links with music technology, which like many technical disciplines is underpinned by an essentially modernist agenda of progress through technological innovation.

There are, naturally, a few significant exceptions to this generalisation. Issue 9.1, marking 'a century of innovation involving sound and technology' (and roughly coinciding with the establishment of the Electroacoustic Music Studies Network), included several articles that directly addressed an important historiographic issue, namely, developing and maintaining source materials for musicologists (Atkinson and Landy 2004; Battier 2004; Ramel 2004; Teruggi 2004). This theme was taken further in volume 11 , which foregrounded such issues as archiving (Chasalow 2006; Dal Farra 2006; Waters 2006), preservation (Emmerson 2006), approaches to technological obsolescence (Bullock and Coccioli 2006; Polfreman, Sheppard, and Dearden 2006; Wetzel 2006; Yong 2006) and the study of tools and techniques as a method in historical musicology (Manning 2006). Issue 18.3 'Re-wiring Electronic Music' - included a few articles documenting recent creative practice that implicitly adopts a historiographic or media archaeological perspective (Paiuk 2013; Parker 2013; Riis 2013). Finally, issue 20.1, marking '20 Years of Organised Sound', had an explicitly retrospective emphasis, and included a range of personal reflections on electroacoustic music's history, as well as an article on canon formation in its literary history (Mooney 2015). However, these articles represent a comparatively small proportion of Organised Sound's total output, and many of them engage with history only from the perspective of its relevance to, or incorporation within, present-day creative practice. Manuella Blackburn's editorial observation that 'all this contemplation appears very current and future focused' (Blackburn 2014) could quite reasonably be applied, then, to the majority of discourse within this journal.

There is, of course, a large body of literature beyond Organised Sound that directly addresses electroacoustic music's history. The first substantial secondary accounts and surveys began to appear in the 1960s (Prieberg 1960; Moles 1960; ORTF 1962; Davies 1968). These focused on composers, studios and technologies, and were often geographically organised, a gambit extended by many key sources that followed (Appleton and Perera 1975; Ernst 1977; Griffiths 1979; Schrader 1982; Holmes 1985; Manning 1985; Chadabe 1997). From the 1990s, disciplinary and methodological horizons broadened, with substantial contributions from the fields of anthropology (Born 1995), sound studies (Kahn 1999; Cox and Warner 2004; Sterne 2012), history of science and technology (Braun 2002; Wittje 2016), science and technology studies (Pinch and Trocco 2004), gender studies (Rodgers 2010), material culture (Weium and Boon 2013), and critical organology (Patteson 2016) to name a few. Focused studies have spotlighted individuals, institutions, and locales that had been omitted or scantily treated in earlier accounts (Kuljuntausta 2008; Niebur 2010; Adkins and Russ 2013; Tazelaar 2013; Helliwell 2016). Reprints and new editions of iconic primary sources ensure that these texts remain important also (Cage 2011; Austin and Kahn 2011; Schaeffer 2012). Any brief survey must necessarily be partial, of course.

Why, then, is there a relative lack of historic perspective within Organised Sound? One possible explanation stems from the demographic of Organised Sound's reader/authorship. As Leigh Landy has recently noted:

most people writing about this music are those who are making it ... In other words, many of these authors might have had difficulty writing from an etic (detached from the community in question) point of view. A significant portion of articles received by the journal are clearly emicthat is, from within the community and, not unusually, largely self-enclosed - offering a fairly tokenistic contextualisation. (Landy 2015: 4)

Although he goes on to note that author-practitioners have become 'better able to look at their subjects from a distance' in recent years, on the whole it appears that approaches to this have tended towards systematic 
rather than historical musicology, that is, authors have tended to frame their arguments and analyses in terms of abstract formalisms rather than by historic or historiographic contextualisation.

Furthermore, where authors have adopted a historic perspective, there seems often to have been a reluctance to deviate from a handful of well-trodden narratives about electroacoustic music's history that stem from the activities of a few 'canonised' men (and, where applicable, their associated institutions). In Europe-focused accounts, the most obvious of these are Pierre Schaeffer - invariably cast as the 'inventor of musique concrète' (e.g. Kane 2007: 15; at the time of writing, Schaeffer's name has featured in the titles of no fewer than fourteen Organised Sound articles) - and Karlheinz Stockhausen and his (N)WDR associates typically cast as the progenitors of the 'rival' approach of elektronische Musik (e.g. Harrison 1998: 117). John Cage and Edgard Varèse are often jointly associated with the 'liberation' of all sounds as potentially musical (e.g. Cox 2009: 25), while Max Mathews is often described as 'the father of computer music' (e.g. Charrieras and Mouillot 2015: 191). The point is not necessarily that such statements are 'wrong', rather, that collectively they reify a standard narrative that risks becoming an unquestioned part of Organised Sound's collective emic perspective. If we want to broaden this perspective, then we will need to look for alternatives to, or extensions of, this standard narrative.

In April 2016, the editors staged a conference at the Science Museum, London, entitled 'Alternative Histories of Electronic Music' - AHEM. ${ }^{1}$ In the call for participation, delegates were invited to address aspects of electronic music's history that, they felt, had been neglected, marginalised, or simply not considered in previous accounts - hence 'alternative'. The precise range of topics was deliberately left open; it was simply suggested that delegates might focus on little-known individuals, institutions, or artefacts, perspectives absent from 'standard' accounts (however defined), and/or promising methodological approaches such as those found in science and technology studies (STS). The response to our call was encouraging: we received some 110 abstracts - far exceeding the number that could be accommodated, even after extending the conference to three full days. The volume of submissions alone demonstrated that much of this research had clearly been waiting to be given a place/space in the field of electroacoustic music studies, and that the time was ripe for an increased attention to issues of history and historiography within this discipline.

${ }^{1}$ See J. Mooney, T. Boon and D. Schampaert (eds.), 'International Conference: Alternative Histories of Electronic Music' (University of Leeds, 2016), https://doi.org/10.5518/160.
The call for papers for this special issue was similar to that of the conference that preceded it, and likewise generated a high number of submissions, such that, unusually, there are no off-topic articles included here. Although some of the articles began their life as presentations delivered at the AHEM conference, the majority were developed independently of it, further illustrating the timeliness of the theme.

Most of the articles presented here challenge the standard narrative in one way or another; however, this special issue was not motivated by a desire to reject previous scholarship on electroacoustic music's history. Rather, it is supposed to serve as an illustration that all history is contingent: no account can be complete in every detail; none can accommodate all viewpoints, or interrogate all sources. In this respect this special issue can be seen as part of a wider musicological trend; the product of, as Georgina Born has put it, 'a widespread sense that the historiographical foundations of music studies would benefit from being renewed' (Born 2010: 238). Neither is the aim, here, to create a new conveniently reductive historic 'context' to replace the old one. Echoing Benjamin Piekut, we feel that 'the danger of context is that it accepts and uses as explanations those stabilized contingencies that are themselves the formations that need to be explained' (Piekut 2014: 205). Indeed, many of the articles collected here draw attention to the contingent nature of such familiar narratives. Above all, these articles are supposed to encourage scholars and practitioners to think about the history of electroacoustic music (studies), to productively defamiliarise the familiar narratives and to seed the development of a new historiographic musicology from within the (generally present- and future-facing) electroacoustic music community.

The first three articles explore or problematise the early roots of electroacoustic music. Two of these (Lautour, Cox) address the context within which musique concrète emerged in the 1930s and 1940s, and thus 'open the black box' (Latour 1987: 1-17) of a creative practice that is taken as axiomatic in many accounts of electroacoustic music's history. The other (Wilson) goes even further and bypasses that context altogether, replacing it with a series of vignettes from the nineteenth century that have rarely if ever found their way into the standard accounts.

Daniel Wilson's contribution has something of Gibson and Sterling's counterfactual novel The Difference Engine, which imagines a Victorian world of information technology come early courtesy of a more successful Charles Babbage. In Wilson's account, electronic music - or rather, electrical music - flourished in the music halls in the hands of one Johann Baptist Schalkenbach, in the telephonic feedback demonstrations of John Gray McKendrick at the Royal Institution Christmas Lectures of 1895, and in 
howling sounds produced - sometimes deliberately, it seems - by the operators of early amplified radio sets. This forceful intervention in the alternative histories that are this issue's concern demonstrates the virtues of leaving behind the well-travelled paths of electronic music historiography, and choosing instead excursions into the long-forgotten and little read literature of house clearances and the forgotten backrooms of second-hand booksellers.

Reuben de Lautour explores questions of the artistic status of what he calls 'the phonographic arts'. Provocatively, he argues that, unlike photography and cinema, the phonographic arts lack a critical tradition because they did not experience an 'Is it art?' moment. Instead, he argues, audio recording is surrounded by an uncritical discourse about verisimilitude - a discourse that he claims 'became embedded in the studio practice of Pierre Schaeffer' despite being 'not well suited to the demands of musique concrète (or indeed any other form of electroacoustic music)'. Through an analysis of Schaeffer's practice and writings, and those of the Canadian World Soundscape Project, Lautour shows how notions of naturalistic fidelity have shaped practice and critical discourse in electroacoustic music.

Geoffrey Cox proposes an alternative (or, perhaps, parallel) history of musique concrète by uncovering the ways in which British documentary soundtracks prefigured many aspects of Pierre Schaeffer's practice. $\mathrm{He}$ is careful not to present this sonic practice as the genealogy for what came after; rather he sketches a series of striking similarities between the two practices under comparison in aesthetic choices over the arrangement of recorded sounds in preference to conventional composition for orchestral instruments. Taking the less well-known example of the film 6:30 Collection (1934), as well as the famous Coalface (1935, made with the collaboration of Benjamin Britten), he highlights parallels between the affordances that filmmakers found in the technological paraphernalia of sound on film, and those that their successors found in the new post-war tape recorders. In doing so, he demonstrates that the axiomatic practices of musique concrète are not unique to that discipline.

The next four articles, rather than interrogate the roots of electroacoustic music, trace (or imply) lineages from past to present. Three of these reconfigure the standard narrative (Levaux; Long et al.; Cameron and Rogalsky). The fourth (Gardner) traces a lineage of smaller scale and scope by focusing on the development of a single electronic musical instrument: the EMS VCS3.

Christophe Levaux traces the history of 'repetitive audio technologies', from the earliest mechanical instruments of the ninth century, through the golden age of mechanical music in the nineteenth century, through the Hammond organ tonewheels of the 1930s, to the experiments with disc and tape loops by Cage, Schaeffer and others in the 1940s and 1950s. By focusing on mechanisms of repetition, he challenges the idea that the musical control of sound through cyclic repetition has its roots in the Cagean/Schaefferian avant garde - a notion that is, he argues, implied in most of the well-known accounts - and urges historians instead to consider 'the long history of musical technology' in their accounts of the organological roots of electroacoustic music.

Jason Long, Jim Murphy, Dale Carnegie and Ajay Kapur present a survey of musical robotics that serves as a history of 'electro-acoustic music without loudspeakers'. Working backwards from the present day (thus following the opposite path to Levaux), they trace the lineage of mechanical actuation in music, from recent applications in popular music, to the experimental instruments and sculptures of Raes, Trimpin and Caulkins in the 1970s. They further trace the origins of the 'concrete musical phrase as a compositional tool' to the pneumatic and hydraulic machines of the nineteenth century and earlier. Like Levaux, Long et al. reframe contemporary electroacoustic music as part of a history that predates both loudspeakers and electricity - surely two of the most fundamental disciplinary axioms.

Laura Cameron and Matt Rogalsky frame nature recording as a precursor of modern soundscape composition. Through their analysis of $A$ Day in the Life of Algonquin Park (1955) - an LP of birdsong recordings by the Canadian sound recordist William W. H. Gunnthey propose the genre of the 'circadian audio portrait', a naturalistic form that 'represent[s] place and time through an artificial assemblage of recorded sequences'. Citing the technical skill and aesthetic choices evident in Algonquin Park, they argue that Gunn should be recognised as a pioneer of soundscape composition and acoustic ecology, despite never having self-identified in those terms (and, indeed, despite his practice having predated the widespread currency of those terms). In doing so, they allude to a parallel genealogy of electroacoustic music, with naturalistic representation rather than acousmatic abstraction as its point of origin.

James Gardner provides an account of the development of the famous EMS VCS3 synthesizer, and thus addresses historic lineage on a smaller scale, and within a narrower scope, than the previous three articles. In discussing the different stages of the instrument's development, from bespoke one-off, to commercial prototype, to commercial availability, he highlights the social construction of the technology (Pinch and Bijker 1984) through the interactions of key protagonists including the members of EMS - Tristram Cary, David Cockerell and Peter Zinovieff - and the Australian composer Don Banks. In an approach not dissimilar to that taken by Pinch and Trocco in their account of the 
development of the Moog synthesizer (Pinch and Trocco 2004), Gardner highlights how the social and technical contingencies that played into the development of this piece of music technology eventually became concretised within the artefact itself.

The next four articles challenge historiographic biases, whether these be related to the kinds of sources consulted and neglected by electroacoustic music historians (Bosma; also implicit in Wilson), the representation of women in, or their exclusion from, discourse surrounding electroacoustic music's history (Morgan, Vàgnerovà), or institutional (non-)representation (Duffy).

Hannah Bosma criticises electroacoustic music's written history for its obsession with technological innovation and its bias in favour of tape-based works. This, she argues, acts against practitioners working in performance-based forms such as live electronic music, or whose contributions to the genre have been musical or conceptual rather than technologically innovative. Through a discussion of three Dutch practitioners whose works 'seem to resist documentation' - Dick Raaijmakers, Michel Waisvisz and Huba de Graaff Bosma urges historians to attend to musical innovation as well as technical, and argues for performance as a form of preservation for live electronic music.

Frances Morgan focuses on representations of women in popular discourse surrounding electroacoustic music history. Drawing examples from new digital media, she argues that images of 'the lone, exceptional female "pioneer" perpetuate a male-dominant view antithetical to the ethos of many of the women thus portrayed, which, furthermore, does nothing to address 'inequalities in the field of music technology [...] that continue in the present day'. By eliding the 'challenges, isolation and discrimination' endured by the women they depict, Morgan argues that such images celebrate rather than critique the marginalisation of women in electroacoustic music, and reduce women's contribution to a trope - a mere 'gender as genre' for a 'presumed majority male, heterosexual audience'.

Lucie Vágnerová calls attention to the countless predominantly female labourers responsible for assembling audio electronics, and thus confronts the uncomfortable fact of their exclusion from electroacoustic music narratives. She addresses the issue of gendered, racialised, neo-colonial labour from a range of perspectives: by acknowledging the role that such labour played - and continues to play - in facilitating the widespread availability of cheap electronic equipment; by highlighting analogous exploitative labour practices in the fashion industry; and by exploring some of the ways in which slave labour has been foregrounded in Afro-futurist art, as opposed to the normally 'sanitised image of technology' that evades issues of race and gender. In doing so, she compels the reader to rethink the category of 'women in electronic music'.
For Paul Duffy, the question is: what if the number of smaller institutions represented in accounts of electroacoustic music's history was greater? Duffy's contribution to this special issue is a detailed account of electronic music at the University of Iowa, his own institution. He shows how in this particular case, it was an approach from outside music - namely, the university's physics department - that set in train more than fifty years of teaching and performance. In giving us a chronological account, appropriately detailed as regards heads of department, equipment and repertoire, he lays out a structure that could, as he suggests, enable comparative accounts of other universities (not dissimilar, in fact, to the approach taken by the British journal Contact in the mid-1970s); foundational empirical studies that will, in due course, enable a more synthetic alternative history to be composed.

Finally, disciplinary (or sub-disciplinary) boundaries take centre stage in two articles that foreground how such boundaries are created (Saladin) and maintained (Pigott) through creative practice with technology, and in two articles that explore how technical and creative disciplines collaborated in the co-advancement of computing technologies and their musical applications (Parolini, Doornbusch). Three of these articles (Saladin, Pigott, Parolini) make explicit use of the methods of science and technology studies (STS).

Matthieu Saladin, through his analysis of the work of Max Neuhaus and Alvin Lucier, explores the role that live electronic music - specifically, experiments with electroacoustic feedback - may have played in catalysing the emergence of a new art-form: that of the sound installation. For both composers, Saladin claims, the use of feedback led to an increased emphasis upon spatiality, rather than timbre, as a primary aesthetic concern, paving the way for an autonomous art-form 'emancipated from the concert hall'. He relates this shift to the fundamental nature of electroacoustic feedback systems, which '[inscribe] the electronic device in a spatial dimension that is linked to the propagation of sound', and thus draws attention to the kinds of 'agency' that technology can exert in the shaping of creative practice.

Jon Pigott compares approaches to the creation and use of electromechanical technologies in music, sound art, kinetic art and industrial contexts. By 'following a technology across disciplinary boundaries' - a method native to STS - he identifies the contrasting and context-sensitive ways in which electromechanical assemblages have been 'black-boxed', and the differing creative approaches this engenders. Drawing upon a range of historic and contemporary examples from experimental music and sound sculpture (and referencing the practice of more than one author from this special issue), Pigott urges electroacoustic musicologists to 'combine and challenge standard divisions between the technical and the 
cultural', as a way of providing new analytical frames for electroacoustic music past and present.

Giuditta Parolini uses a case study of the Italian cellist and composer Pietro Grossi to explore the intersection between music, technology and business in relation to the development of early computer music. She shows how Grossi chose to learn how to program computers so that he could realise his musical ideas; the results were also of value to the computer companies Olivetti-General Electric and Italian IBM, as a way of testing the software and hardware capacities of their machines. Adopting a strongly sociological perspective, Parolini's case study highlights the debt that today's discipline of computer music owes to the efforts of technologically adventurous musicians like Grossi, who were willing to invest considerable effort to bridge what were, at the time, formidable boundaries between the creative and technical disciplines.

Finally, Paul Doornbusch, in his discussion of 'Early Computer Music Experiments in Australia and England', traces the emergence of computer musicmaking applications from the error-checking routines and technical exercises of engineers working on automatic calculation machines in the late 1940s and early 1950s. Representing the earliest known examples of computer music-making, experiments with the Ferranti Mk. 1 and Pilot ACE computers in Manchester, and the Council for Scientific and Industrial Research Automatic Computer (CSIRAC) in Sydney, highlight how computers were 'used musically since the earliest development of those machines', several years before 'the father of computer music' Max Mathews's canonical work on digital synthesis, and Hiller and Isaccson's on algorithmic composition.

The articles collected here show how engaging with issues of history and historiography might help to broaden the sometimes problematically narrow, emic, present-day-focused perspective often adopted within Organised Sound's pages. (Although two-thirds of the authors are composers, or have their own creative practice, none discuss their own work directly.) The articles also demonstrate some of the ways in which historiographic sensitivity can be used to challenge the 'standard' narrative of electroacoustic music's history: by problematizing the early roots of the idiom; by actively seeking connections between past and present practice that upset assumed lineages; by interrogating disciplinary axioms and boundaries; by spotlighting historiographic biases. There remains, of course, much work to be done. We are aware that, with perhaps one borderline case (Vágnerová), the perspective offered in this special issue is exclusively Western; more work is needed to demarginalise non-Western histories of electroacoustic music. Partial as it is, we hope that this collection of articles will help to advance debate, stimulate interest in history and historiography among electroacoustic music's scholars and practitioners, and prompt further research in this area.
We hope that you, the readers of this special issue, like the contributors to the volume and those who were at the conference, accept our proposition that electronic and electroacoustic music become more interesting by the opening-up of this diversity of interpretations. If you do, then we hope you will join us in extending this approach further in the years ahead. We feel that there is still more to be learned by working with our colleagues in science and technology studies (see Bijker, Pinch and Hughes 2012), and in the history of technology. (Echoing Smith and Marx (1994), to what extent does music technology drive music history, for instance?) We are confident that there is much to be learned from visiting the stores of the museums worldwide that hold the instruments that time may have forgotten (e.g. Mooney 2017). We know that some of our colleagues in organology are embarking on a similar journey (e.g. Tresch and Dolan 2013). Who knows? Given musicians' fascination for the pasts of electronic music (e.g. Eno 2013), perhaps we can expect a positive feedback loop from this new approach to give us new kinds of music too.

We would like to extend our thanks to all the authors who have contributed to this special issue, to the numerous peer reviewers who generously and anonymously devoted their time to reading and commenting on the many submissions we received, and to the invited speakers, presenters and delegates of the AHEM conference, many of whom are not represented within these pages, but all of whom were instrumental in establishing the dialogue that led to this special issue. We also thank Leigh Landy for his patience and support in handling a larger number of submissions than expected. This special issue and the conference that preceded it were made possible by a grant from the Arts and Humanities Research Council, as part of the project 'Hugh Davies: Electronic Music Innovator' (ref: AH/M005216/1). Our final thanks go to the AHRC for providing this support.

\author{
James Mooney \\ (j.r.mooney@leeds.ac.uk) \\ Dorien Schampaert \\ (d.schampaert@leeds.ac.uk) \\ Tim Boon \\ (tim.boon@sciencemuseum.ac.uk)
}

\section{REFERENCES}

Adkins, M. and Russ, M. (eds.) 2013. The Roberto Gerhard Companion. Burlington, VT: Routledge.

Appleton, J. H. and Perera, R. (eds.) 1975. The Development and Practice of Electronic Music. Englewood Cliffs, NJ: Prentice-Hall. 
Atkinson, S. and Landy, L. 2004. The ElectroAcoustic Resource Site (EARS): Philosophy, Foundation and Aspirations. Organised Sound 9(1): 79-85.

Austin, L. and Kahn, D. (eds.) 2011. Source: Music of the Avant-Garde, 1966-1973. Berkeley: University of California Press.

Battier, M. 2004. Electroacoustic Music Studies and the Danger of Loss. Organised Sound 9(1): 47-53.

Bijker, W., Pinch, T. and Hughes, T. 2012. The Social Construction of Technological Systems: New Directions in the Sociology and History of Technology. Anniversary edition. Cambridge, MA: MIT Press.

Blackburn, M. 2014. Editorial. Organised Sound 19(2): 107-09.

Born, G. 1995. Rationalizing Culture: IRCAM, Boulez and the Institutionalization of the Musical Avant-Garde. London: University of California Press.

Born, G. 2010. For a Relational Musicology: Music and Interdisciplinarity, Beyond the Practice Turn: The 2007 Dent Medal Address. Journal of the Royal Musical Association 135(2): 205-43.

Braun, H.-J. (ed.) 2002. Music and Technology in the Twentieth Century. Baltimore, MD: Johns Hopkins University Press.

Bullock, J. and Coccioli, L. 2006. Modernising Musical Works Involving Yamaha DX-Based Synthesis: A Case Study. Organised Sound 11(3): 221-27.

Cage, J. 2011. Silence. London: Marion Boyars.

Chadabe, J. 1997. Electric Sound: The Past and Promise of Electronic Music. Upper Saddle River, NJ: Prentice Hall.

Charrieras, D. and Mouillot, F. 2015. Getting Out of the Black Box: Analogising the Use of Computers in Electronic Music and Sound Art. Organised Sound 20(2): 191-99.

Chasalow, E. 2006. Composing from Memory: The Convergence of Archive Creation and Electroacoustic Composition. Organised Sound 11(1): 63-71.

Cox, C. 2009. Sound Art and the Sonic Unconscious. Organised Sound 14(1): 19-26.

Cox, C. and Warner, D. (eds.) 2004. Audio Culture: Readings in Modern Music. London and New York: Continuum.

Dal Farra, R. 2006. Something Lost, Something Hidden, Something Found: Electroacoustic Music by Latin American Composers. Organised Sound 11(2): 131-42.

Davies, H. 1968. Répertoire International Des Musiques Électroacoustiques/International Electronic Music Catalog. Paris and Trumansburg, NY: MIT Press.

Emmerson, S. 2006. In What Form Can Live Electronic Music Live On? Organised Sound 11(3): 209-19.

Eno, B. 2013. Foreword. In F. Weium and T. Boon (eds.) Material Culture and Electronic Sound. Washington, DC and Lanham, MD: Smithsonian Institution Scholarly Press and Rowman \& Littlefield.

Ernst, D. 1977. The Evolution of Electronic Music. New York: Schirmer Books.

Griffiths, P. 1979. A Guide to Electronic Music. New York: Thames \& Hudson.

Harrison, J. 1998. Sound, Space, Sculpture: Some Thoughts on the 'What', 'How' and 'Why' of Sound Diffusion. Organised Sound 3(2): 117-27.

Helliwell, I. 2016. Tape Leaders. Cambridge: Sound on Sound.

Holmes, T. B. 1985. Electronic and Experimental Music: History, Instruments, Technique, Performers, Recordings. New York: Charles Scribner.
Kahn, D. 1999. Noise, Water, Meat: A History of Sound in the Arts. London: MIT Press.

Kane, B. 2007. L'Objet Sonore Maintenant: Pierre Schaeffer, Sound Objects and the Phenomenological Reduction. Organised Sound 12(1): 15-24.

Kuljuntausta, P. 2008. First Wave: A Microhistory of Early Finnish Electronic Music. Helsinki: Like.

Landy, L. 2015. 20 Years of Organised Sound: Looking Back and Forward. Organised Sound 20(1): 1-9.

Latour, B. 1987. Science in Action: How to Follow Scientists and Engineers Through Society. Cambridge, MA: Harvard University Press.

Manning, P. 1985. Electronic and Computer Music. Oxford: Clarendon Press.

Manning, P. 2006. The Significance of Techné in Understanding the Art and Practice of Electroacoustic Composition. Organised Sound 11(1): 81-90.

Moles, A. 1960. Les Musiques Expérimentales. Paris, Zürich and Brussels: Editions du Cercle d'Art Contemporain.

Mooney, J. 2015. Hugh Davies's Electronic Music Documentation 1961-1968. Organised Sound 20(1): 111-121.

Mooney, J. 2017. The Hugh Davies Collection: Live Electronic Music and Self-Built Electro-Acoustic Musical Instruments, 1967-75. Science Museum Group Journal 7.

Niebur, L. 2010. Special Sound: The Creation and Legacy of the B.B.C. Radiophonic Workshop. New York: Oxford University Press.

ORTF. 1962. Répertoire International des Musiques Expérimentales: Studios, Oeuvres, Equipements, Bibliographie. Paris: Service de la Recherche de la RadiodiffusionTelévision Française.

Paiuk, G. 2013. Tactility, Traces and Codes: Reassessing Timbre in Electronic Media. Organised Sound 18(3): 306-13.

Parker, L. E. 2013. Repurposing the Past: The Phantastron and Appropriating History as a DIY Approach. Organised Sound 18(3): 292-98.

Patteson, T. W. 2016. Instruments for New Music: Sound, Technology, and Modernism. Oakland, CA: University of California Press.

Piekut, B. 2014. Actor-Networks in Music History: Clarifications and Critiques. Twentieth-Century Music 11(2): 191-215.

Pinch, T. J. and Bijker, W. E. 1984. The Social Construction of Facts and Artefacts: Or How the Sociology of Science and the Sociology of Technology Might Benefit Each Other. Social Studies of Science 14(3): 399-441.

Pinch, T. and Trocco, F. 2004. Analog Days: The Invention and Impact of the Moog Synthesizer. Cambridge, MA: Harvard University Press.

Polfreman, R., Sheppard, D. and Dearden, I. 2006. Time to Re-Wire? Problems and Strategies for the Maintenance of Live Electronics. Organised Sound 11(3): 229-42.

Prieberg, F. K. 1960. Musica ex Machina: Über das Verhältnis von Musik und Technik. Berlin: Ullstein.

Ramel, S. 2004. Conservation and Restoration of Electroacoustic Musical Instruments at the Musée de $\mathrm{La}$ Musique, Paris. Organised Sound 9(1): 87-90.

Riis, M. 2013. The Media Archaeological Repairman. Organised Sound 18(3): 255-65.

Rodgers, T. 2010. Pink Noises: Women on Electronic Music and Sound. Durham, NC: Duke University Press. 
Schaeffer, P. 2012. In Search of a Concrete Music. Trans. C. North and J. Dack. Berkeley, CA: University of California Press.

Schrader, B. 1982. Introduction to Electro-Acoustic Music. Englewood Cliffs, NJ: Longman Higher Education.

Smith, M. R. and Marx, L. (eds.) 1994. Does Technology Drive History? The Dilemma of Technological Determinism. London: MIT Press.

Sterne, J. (ed.) 2012. The Sound Studies Reader. London: Routledge.

Tazelaar, K. 2013. On the Threshold of Beauty: Philips and the Origins of Electronic Music in the Netherlands 1925-1965. Rotterdam: NAI Publishers.

Teruggi, D. 2004. Electroacoustic Preservation Projects: How to Move Forward. Organised Sound 9(1): 55-62.

Tresch, J. and Dolan, E. I. 2013. Toward a New Organology: Instruments of Music and Science. Osiris 28: 278-98.
Waters, S. 2006. Making the Archive and Archiving the Making: Insights and Outcomes from a Major Research Project. Organised Sound 11(2): 143-47.

Weium, F. and Boon, T. (eds.) 2013. Material Culture and Electronic Sound. Washington, DC and Lanham, MD: Smithsonian Institution Scholarly Press and Rowman \& Littlefield.

Wetzel, D. B. 2006. A Model for the Conservation of Interactive Electroacoustic Repertoire: Analysis, Reconstruction, and Performance in the Face of Technological Obsolescence. Organised Sound 11(3): 273-84.

Wittje, R. 2016. The Age of Electroacoustics: Transforming Science and Sound. Cambridge, MA: MIT Press.

Yong, K. 2006. Electroacoustic Adaptation as a Mode of Survival: Arranging Giacinto Scelsis Aitsi Pour Piano Amplifée (1974) for Piano and Computer. Organised Sound 11(3): 243-54. 